\title{
Seleksi Galur-galur Dihaploid Padi Hitam pada Uji Daya Hasil Lanjutan
}

\section{Doubled Haploid Lines Selection of Black Rice in Advanced Yield Trial}

\author{
Danu Kuncoro', Mutiyara Sani², Bambang Sapta Purwoko ${ }^{2 *}$, Iswari Saraswati Dewi ${ }^{3}$, \\ Willy Bayuardi Suwarno ${ }^{2}$, Awang Maharijaya ${ }^{2}$, dan Eny Widajati² \\ ${ }^{1}$ Program Studi Pemuliaan dan Bioteknologi Tanaman, Sekolah Pascasarjana, Institut Pertanian Bogor \\ ${ }^{2}$ Departemen Agronomi dan Hortikultura, Fakultas Pertanian, Institut Pertanian Bogor \\ (IPB University), Jl. Meranti, Kampus IPB Darmaga, Bogor 16680, Indonesia \\ ${ }^{3}$ Balai Besar Penelitian dan Pengembangan Bioteknologi dan Sumber Daya Genetik Pertanian \\ Jl. Tentara Pelajar No. 3A, Bogor 16111, Indonesia
}

Diterima 19 Agustus 2021/Disetujui 3 Desember 2021

\begin{abstract}
Black rice becomes a source of carbohydrate with health benefits. Yield trial is an important step for the success of black rice breeding. This study aimed at obtaining information on agronomic performance of doubled haploid lines of black rice and selecting the best doubled haploid black rice lines with good agronomic characters and high yielding for multilocation yield trials. This study was conducted from November 2019 until July 2020 in Bogor, West Java and Malang, East Java. Twenty-three doubled haploid black rice lines and three check varieties namely Aek Sibundong, Jeliteng, and Inpari 24 were used as plant genetic materials. This study was arranged in a randomized complete block design with three replications for each treatment. The result revealed that interaction of genotype and environment was significant on all observed traits except on grain filling period according to analysis of variance. Fourteen doubled haploid rice lines were selected based on weighted selection index. These lines showed number of productive tillers per hill ranged from 15.8 to 25.9, early maturity from 115.2 to 121.9 days after sowing, and high productivity $\left(>5.4\right.$ ton $\left.\mathrm{ha}^{-1}\right)$. The agronomic performance and yield of the doubled haploid rice lines selected in this study required further testing through a multi-site test to obtain a candidate for new high yielding variety for black rice.
\end{abstract}

Keywords: good agronomic, rice anther culture, selection criteria, selection index

\section{ABSTRAK}

Padi hitam merupakan sumber karbohidrat yang bermanfaat untuk kesehatan. Pengujian daya hasil merupakan tahapan penting dalam menentukan keberhasilan pemuliaan padi beras hitam. Tujuan penelitian ini ialah untuk memperoleh informasi keragaan agronomi dan menyeleksi galur-galur dihaploid padi beras hitam yang memiliki penampilan agronomi baik dan berdaya hasil tinggi untuk pengujian multi lokasi. Penelitian ini dilakukan dari bulan November 2019 sampai Juli 2020 di Bogor, Jawa Barat dan Malang, Jawa Timur. Sebanyak 23 galur dihaploid padi hitam yang memiliki sifat agronomi baik dengan produktivitas tinggi dan 3 varietas pembanding yaitu Aek Sibundong, Jeliteng, dan Inpari 24 digunakan sebagai materi genetik. Studi ini menggunakan rancangan rancangan kelompok lengkap teracak dengan 3 ulangan pada setiap percobaan. Hasil penelitian menunjukkan bahwa interaksi genotipe dan lingkungan berpengaruh nyata terhadap semua karakter pengamatan kecuali pada karakter lama pengisian gabah berdasarkan analisis keragaman. Sebanyak 14 galur yang terseleksi berdasarkan indeks terboboti memiliki karakteristik jumlah anakan produktif per rumpun dari 15.8 hingga 25.9, umur panen genjah dari 115.2 to 121.9 hari setelah semai, dan produktivitas $>5.4$ ton ha ${ }^{-1}$. Keragaan agronomi dan daya hasil galur-galur dihaploid padi yang terseleksi pada penelitian ini memerlukan pengujian lebih lanjut melalui uji multi lokasi untuk memperoleh calon varietas unggul baru padi beras hitam.

Kata kunci: agronomi baik, indeks seleksi, kriteria seleksi, kultur antera padi

\footnotetext{
* Penulis untuk korespondensi. e-mail: bspurwoko@apps.ipb.ac.id
} 


\section{PENDAHULUAN}

Padi hitam merupakan salah satu sumber karbohidrat yang dikonsumsi oleh sebagian masyarakat Asia untuk tujuan kesehatan (Muthayya et al., 2014). Di Indonesia, beras hitam banyak dikembangkan sebagai bahan dasar makanan tradisional, minuman, dan makanan ringan untuk tujuan kesehatan. Beras hitam memiliki kandungan antioksidan yang tinggi dan kandungan gula yang rendah sehingga bermanfaat untuk pencegahan penyakit kanker dan diabetes (Pratiwi dan Purwestri, 2017; Raghuvanshi et al., 2017; Shao et al., 2018).

Pengembangan varietas padi hitam dapat dipercepat dengan pemanfaatan metode kultur antera. Metode ini bermanfaat dalam peningkatan efisiensi proses seleksi serta dapat menghemat tenaga dan biaya karena galur dihaploid homozigot diperoleh pada satu generasi sehingga dapat langsung dievaluasi (Dewi dan Purwoko, 2012). Dari penelitian yang dilakukan oleh Mawaddah et al. (2018) diperoleh galur dihaploid padi merah dan padi hitam yang telah dikarakterisasi di rumah kaca. Galur-galur tersebut dilanjutkan dengan pengujian daya hasil pendahuluan dan terseleksi galur-galur dihaploid padi hitam dengan sifat agronomi baik (Alsabah et al., 2019).

Salah satu karakter penting dalam pemuliaan padi hitam ialah karakter produktivitas. Genotipe berdaya hasil tinggi dapat diperoleh jika seleksi langsung dilakukan pada karakter produktivitas. Islam et al. (2017) menerangkan bahwa seleksi secara langsung pada karakter produktivitas tidak efektif dikarenakan banyak gen yang mengendalikan karakter tersebut. Oleh karena itu, seleksi genotipe dengan produktivitas tinggi akan lebih efektif jika melibatkan karakter komponen hasil seperti jumlah anakan produktif dan bobot 1000 butir gabah bernas (Akbar et al., 2021).

Metode seleksi indeks dapat digunakan untuk melakukan seleksi dengan beberapa karakter. Genotipe yang terpilih merupakan genotipe dengan kombinasi karakterkarakter yang diinginkan (Akbar et al., 2019b; Hidayatullah et al., 2018; Silva et al., 2016). Indeks seleksi digunakan untuk menyeleksi genotipe yang didasarkan pada beberapa karakter agronomi dengan pembobotan sesuai dengan nilai ekonominya (Ramos et al., 2014; Gazal et al., 2017; Cui et al., 2020). Tujuan penelitian ini ialah untuk mengevaluasi keragaan agronomi dan menyeleksi galur-galur dihaploid padi hitam yang memiliki penampilan agronomi baik dan berdaya hasil tinggi untuk pengujian multi lokasi.

\section{BAHAN DAN METODE}

Penelitian ini dilaksanakan antara November 2019 sampai Juli 2020 di Bogor, Jawa Barat dan Malang, Jawa Timur. Dua puluh tiga galur dihaploid padi yang memiliki penampilan agronomi baik dan berdaya hasil tinggi dan 3 varietas cek (Aek Sibundong, Jeliteng, dan Inpari 24) digunakan sebagai materi genetik. Studi ini menggunakan rancangan kelompok lengkap teracak dengan genotipe sebagai faktor perlakuan dan 3 ulangan pada setiap percobaan. Setiap unit percobaan memiliki ukuran petak sebesar $3 \mathrm{~m}$ x $3 \mathrm{~m}$. Penanaman bibit dilakukan pada 21 hari setelah semai (HSS) dengan jarak tanam $25 \mathrm{~cm}$ x 25 cm. Pupuk Urea, SP 36, dan $\mathrm{KCl}$ diaplikasikan pada setiap petak dengan dosis pemupukan berturut-turut adalah 200, 100, dan $100 \mathrm{~kg} \mathrm{ha}^{-1}$. Satu minggu setelah tanam (MST) dilakukan pemupukan SP 36 dan $\mathrm{KCl}$ untuk satu dosis, sedangkan pemupukan Urea diaplikasikan pada 1 MST, 4 MST, dan 7 MST dengan sepertiga dosis setiap aplikasi. Hama dan penyakit dikendalikan sesuai standar budidaya tanaman padi.

Karakter agronomi yang diukur meliputi tinggi tanaman yang diukur sebelum panen, jumlah anakan vegetatif, jumlah anakan produktif yang diukur menjelang panen, umur berbunga diamati saat $50 \%$ setiap plot berbunga, lama pengisian gabah yang dihitung dari umur pembungaan hingga umur panen, umur panen yang diamati saat $80 \%$ padi per plot menunjukkan warna kuning, panjang malai, jumlah gabah isi per malai, jumlah gabah hampa per malai, jumlah gabah total per malai, persentase gabah isi per malai, bobot 1,000 butir gabah bernas, dan produktivitas diperoleh dari konversi bobot gabah per petak menjadi bobot gabah per hektar.

Data pengamatan dianalisis dengan analisis ragam gabungan dan nilai tengah diuji lanjut dengan uji beda nyata terkecil (BNT) pada taraf 5\%. Karakter agronomi penting untuk seleksi (X) diberi pembobotan sesuai Hidayatullah et al. (2018) yaitu produktivitas: +5 , jumlah anakan produktif: +1 , jumlah gabah isi per malai: +1 , persentase gabah isi per malai: +1 , jumlah gabah total per malai: +2 , bobot 1,000 gabah bernas: +1 , dan umur panen: -1 . Indeks seleksi terboboti mengacu pada Sandhu et al. (2019). Nilai indeks yang diperoleh diurutkan dan digunakan untuk menyeleksi genotipe terbaik. Perangkat lunak yang digunakan dalam analisis adalah STAR 2.0.1 IRRI dan Microsoft Excel 2019 untuk analisis ragam, penentuan heritabilitas, dan indeks seleksi.

\section{HASIL DAN PEMBAHASAN}

\section{Analisis Ragam dan Keragaan Karakter Agronomi}

Analisis ragam gabungan menggambarkan bahwa perlakuan genotipe $(\mathrm{G})$ memberikan pengaruh nyata pada semua karakter (Tabel 1). Lokasi (E) berpengaruh nyata terhadap semua karakter, kecuali pada karakter jumlah anakan vegetatif, umur panen, bobot 1,000 butir gabah, dan produktivitas. Interaksi G x E berpengaruh nyata terhadap semua karakter, kecuali pada lama pengisian gabah. Interaksi G x E ini terjadi apabila respon genotipe berubah pada lingkungan yang berbeda (Akbar et al., 2021; Hidayatullah et al., 2018; Sivakumar et al., 2017).

Keragaan karakter agronomi disajikan pada Tabel 2 dan Tabel 3. Galur YD6-1-1-2 memiliki tinggi tanaman tertinggi $(116.4 \mathrm{~cm})$, sementara MW4-40-1-2 memiliki tinggi tanaman terendah $(82.6 \mathrm{~cm})$ (Tabel 2). Tinggi tanaman menjadi salah satu karakter penting karena akan 
Tabel 1. Analisis ragam gabungan karakter agronomi galur-galur dihaploid padi hitam dan pembandingnya

\begin{tabular}{|c|c|c|c|c|}
\hline \multirow{2}{*}{ Karakter } & \multicolumn{3}{|c|}{ F hitung } & \multirow{2}{*}{$\begin{array}{c}\text { Koefisien } \\
\text { keragaman }(\%)\end{array}$} \\
\hline & Genotipe (G) & Lokasi (E) & $\mathrm{G} \times \mathrm{E}$ & \\
\hline Tinggi tanaman $(\mathrm{cm})$ & $29.04 * *$ & $60.15 * *$ & $4.93 * *$ & 3.53 \\
\hline Jumlah anakan vegetatif & $22.74 * *$ & $2.61 \mathrm{tn}$ & $3.51 * *$ & 8.53 \\
\hline Jumlah anakan produktif & $21.04 * *$ & $11.46^{*}$ & $3.40 * *$ & 8.73 \\
\hline Umur berbunga (HSS) & $4.76^{* *}$ & $87.60 * *$ & $1.84 *$ & 2.51 \\
\hline Lama pengisian gabah (hari) & $5.40 * *$ & $4,037.88 * *$ & $1.36 \mathrm{tn}$ & 6.03 \\
\hline Umur panen (HSS) & $10.38 * *$ & $6.51 \mathrm{tn}$ & $10.38 * *$ & 1.27 \\
\hline Panjang malai (cm) & $83.66^{* *}$ & $47.34 * *$ & $7.21 * *$ & 2.75 \\
\hline Jumlah gabah isi per malai & $68.96 * *$ & $92.70 * *$ & $14.69 * *$ & 8.16 \\
\hline Jumlah gabah hampa per malai & $29.88 * *$ & $66.64 * *$ & $6.39 * *$ & 11.83 \\
\hline Jumlah gabah total per malai & $81.51 * *$ & $13.57 * *$ & $10.90 * *$ & 8.58 \\
\hline Persentase gabah isi per malai (\%) & $10.16^{* *}$ & $122.27 * *$ & $3.79 * *$ & 6.68 \\
\hline Bobot 1,000 butir gabah bernas (g) & $43.99 * *$ & $0.00 \mathrm{tn}$ & $4.47 * *$ & 3.53 \\
\hline Produktivitas (ton ha' ${ }^{-1}$ ) & $3.03 * *$ & 7.06tn & $4.52 * *$ & 13.84 \\
\hline
\end{tabular}

Keterangan: HSS $=$ hari setelah semai, $* *=$ berpengaruh nyata pada $\mathrm{p}<0.01 ; *=$ berpengaruh nyata pada $\mathrm{p}<0.05$; $\mathrm{tn}=$ tidak berpengaruh nyata

berpengaruh terhadap tingkat kerebahan batang. Umumnya tipe padi rendah $(<80 \mathrm{~cm})$ cenderung tahan rebah (IRRI, 2013). Jumlah anakan vegetatif galur yang diuji berkisar antara 18.5-31.2 anakan per rumpun (Tabel 2). Genotipe dengan jumlah anakan vegetatif banyak berpotensi memiliki jumlah anakan produktif yang optimum. Jumlah anakan produktif berkisar antara 15.2-26.6 anakan produktif per rumpun (Tabel 2). Berdasarkan pengelompokan jumlah anakan produktif menurut IRRI (2013) diperoleh bahwa semua galur yang diuji berada pada kategori sedang hingga sangat banyak. Galur MW3-12-1-4 (25.9 anakan), MW324-2-1 (25.4 anakan), MW3-36-1-2 (26.6 anakan), MW382-1-1 (25.9 anakan), dan MW4-40-1-2 (26.0 anakan) memiliki jumlah anakan produktif berbeda nyata lebih banyak dibandingkan varietas pembanding Jeliteng (21.1 anakan). Galur-galur memiliki potensi produktivitas tinggi karena banyaknya anakan produktif akan berpeluang meningkatkan jumlah gabah (Seyoum et al., 2012).

Umur berbunga berkisar antara 82.7-90.4 HSS (Tabel 2). Galur MW4-40-1-2 merupakan galur dengan umur tercepat dan berbeda nyata dengan varietas Jeliteng (89.9 HSS). Lama pengisian gabah berkisar antara 26.5-34.0 hari. Umur panen berkisar antara 115.7-122.0 HSS. Sebanyak 9 galur memiliki umur panen berbeda nyata lebih cepat dibandingkan varietas Jeliteng (121.4 HSS). Berdasarkan pengelompokan umur panen oleh IRRI seluruh galur yang diuji memiliki kategori umur genjah dari 104 hingga 124 HSS (IRRI, 2013).

Panjang malai genotipe yang diuji berkisar antara $19.7-26.0 \mathrm{~cm}$ (Tabel 2). Sebanyak 3 galur memiliki panjang malai tidak berbeda nyata dengan varietas Jeliteng $(26.9 \mathrm{~cm})$.
Jumlah gabah isi per malai berkisar antara 71.8-176.0 butir (Tabel 3). Jumlah gabah isi per malai pada galur YD5-37-11 (176.0 butir) dan YD5-37-1-2 (175.4 butir) berbeda nyata lebih banyak dibandingkan dengan varietas Jeliteng (158.2 butir). Peningkatan jumlah gabah ini juga berdampak pada peningkatan produktivitas (Seyoum et al., 2012). Kisaran jumlah gabah hampa per malai yaitu 10.6-104.2 butir (Tabel 3). Jumlah gabah total per malai berkisar antara 92.5-279.6 butir (Tabel 3). Galur dengan jumlah gabah total per malai yang berbeda nyata lebih banyak dibandingkan varietas Jeliteng (196.1 butir) yaitu galur YD5-37-1-1 (265.0 butir), YD5-37-1-2 (279.6 butir), dan YD6-1-1-2 (229.8 butir).

Persentase gabah isi per malai berkisar antara 61.9$88.3 \%$ (Tabel 3). Persentase gabah isi berkontribusi dalam produktivitas yang tinggi (Sabri et al., 2021). Bobot 1,000 butir gabah bernas berkisar antara 21.0-30.6 g (Tabel 3). Produktivitas genotipe yang diuji berkisar antara 4.9 ton ha $^{-1}$ (YD6-1-1-2) -7.3 ton ha $^{-1}$ (Inpari 24). Produktivitas varietas Jeliteng (5.8 ton $\mathrm{ha}^{-1}$ ) berbeda nyata lebih kecil dibandingkan varietas Inpari 24. Seluruh genotipe yang diuji memiliki produktivitas tidak berbeda nyata dengan varietas Jeliteng. Hal tersebut menggambarkan galur yang diuji memiliki produktivitas yang sama baiknya dengan varietas pembanding Jeliteng, sehingga nantinya dapat menjadi calon varietas rekomendasi.

\section{Indeks Seleksi Terboboti}

Seleksiyangdilakukanpadapenelitianinimenggunakan beberapa karakter penting yaitu produktivitas, jumlah anakan produktif, jumlah gabah isi per malai, persentase gabah isi 
Tabel 2. Rata-rata keragaan karakter komponen hasil genotipe padi hitam dan pembandingnya

\begin{tabular}{|c|c|c|c|c|c|c|c|}
\hline Genotipe & $\begin{array}{l}\text { Tinggi } \\
\text { tanaman } \\
(\mathrm{cm})\end{array}$ & $\begin{array}{c}\text { Jumlah } \\
\text { anakan } \\
\text { vegetatif }\end{array}$ & $\begin{array}{c}\text { Jumlah } \\
\text { anakan } \\
\text { produktif }\end{array}$ & $\begin{array}{l}\text { Umur } \\
\text { berbunga } \\
\text { (HSS) }\end{array}$ & $\begin{array}{c}\text { Lama } \\
\text { pengisian } \\
\text { gabah (hari) }\end{array}$ & $\begin{array}{l}\text { Umur } \\
\text { panen } \\
\text { (HSS) }\end{array}$ & $\begin{array}{c}\text { Panjang } \\
\text { malai } \\
(\mathrm{cm})\end{array}$ \\
\hline MW3-12-1-3 & 104.9 & 28.3 & 22.7 & 89.9 & 32.0 & 121.8 & 20.7 \\
\hline MW3-12-1-4 & 101.6 & 30.8 & 25.9 & 89.0 & 32.7 & 121.7 & 20.1 \\
\hline MW3-24-2-1 & 105.0 & 30.3 & 25.4 & 87.9 & 32.7 & 120.5 & 19.7 \\
\hline MW3-36-1-1 & 104.1 & 27.8 & 24.3 & 88.7 & 27.0 & 115.7 & 22.0 \\
\hline MW3-36-1-2 & 102.9 & 29.6 & 26.6 & 90.4 & 26.5 & 116.8 & 21.1 \\
\hline MW3-58-2-3 & 104.5 & 26.5 & 23.8 & 88.7 & 32.8 & 121.5 & 20.6 \\
\hline MW3-58-2-4 & 105.2 & 28.9 & 24.2 & 90.4 & 31.7 & 122.0 & 20.2 \\
\hline MW3-82-1-1 & 104.8 & 31.2 & 25.9 & 88.4 & 33.0 & 121.3 & 20.0 \\
\hline MW4-40-1-2 & 82.6 & 28.2 & 26.0 & 82.7 & 33.7 & 116.4 & 21.5 \\
\hline MW5-19-1-1 & 101.4 & 26.1 & 22.7 & 85.5 & 31.0 & 116.5 & 22.8 \\
\hline MW6-60-1-1 & 93.5 & 24.0 & 20.8 & 86.2 & 30.7 & 116.9 & 22.5 \\
\hline YD1-61-1-1 & 98.9 & 22.6 & 20.2 & 88.2 & 32.5 & 120.7 & 25.3 \\
\hline YD1-71-1-1 & 100.6 & 21.0 & 18.2 & 89.4 & 32.5 & 121.9 & 24.4 \\
\hline YD1-51-2-1 & 93.4 & 21.6 & 19.7 & 86.9 & 31.7 & 118.5 & 23.9 \\
\hline YD1-51-2-2 & 93.1 & 22.6 & 21.0 & 85.0 & 34.0 & 119.0 & 24.0 \\
\hline YD1-51-2-3 & 90.7 & 21.9 & 20.6 & 84.7 & 33.4 & 118.0 & 24.5 \\
\hline YD1-48-1-2 & 91.9 & 22.9 & 20.3 & 87.0 & 32.7 & 119.7 & 26.1 \\
\hline YD5-10-1-2 & 87.1 & 21.6 & 18.6 & 85.8 & 32.2 & 118.0 & 24.7 \\
\hline YD5-37-1-1 & 101.2 & 19.1 & 16.0 & 86.2 & 33.4 & 119.5 & 26.7 \\
\hline YD5-37-1-2 & 95.0 & 18.7 & 16.2 & 87.2 & 33.5 & 120.7 & 26.7 \\
\hline YD5-37-1-3 & 106.3 & 18.5 & 15.2 & 85.0 & 33.7 & 118.7 & 24.0 \\
\hline YD6-1-1-1 & 115.1 & 19.1 & 15.8 & 88.7 & 32.4 & 121.0 & 23.9 \\
\hline YD6-1-1-2 & 116.4 & 19.9 & 17.4 & 87.0 & 34.0 & 121.0 & 25.3 \\
\hline Aek Sibundong & 106.1 & 27.0 & 23.4 & 88.2 & 30.5 & 118.7 & 26.9 \\
\hline Jeliteng & 104.5 & 24.2 & 21.1 & 89.9 & 31.5 & 121.4 & 26.9 \\
\hline Inpari 24 & 103.8 & 23.7 & 20.9 & 88.9 & 32.7 & 121.5 & 26.3 \\
\hline Rata-rata & 100.4 & 24.5 & 21.3 & 87.5 & 32.1 & 119.6 & 23.5 \\
\hline BNT (0.05) & 5.7 & 3.4 & 3.0 & 3.5 & 4.2 & 2.5 & 1.1 \\
\hline
\end{tabular}

per malai, jumlah gabah total per malai, bobot 1,000 gabah bernas, dan umur panen. Karakter-karakter tersebut juga digunakan dalam seleksi yang dilakukan oleh Hidayatullah et al. (2018), Anshori et al. (2019), dan Akbar et al. (2021). Pembobotan pada karakter seleksi dilakukan berdasarkan kepentingan nilai ekonomi masing-masing karakter dan relevansinya dengan tujuan program pemuliaan tanaman. Penentuan bobot dapat dilakukan juga menggunakan metode analisis komponen utama (Akbar et al. 2019a; Anshori et al. 2019; Anshori et al., 2021). Hal tersebut dilakukan dengan tujuan mengurangi subyektivitas dalam pemilihan genotipe. Nilai positif dan negatif dari pembobotan menggambarkan arah seleksi.
Nilai indeks terboboti berkisar antara-10.39(MW3-582-4) hingga 10.35 (Inpari 24) (Tabel 3). Seleksi berdasarkan nilai indeks menghasilkan 14 galur (nilai indeks tertinggi) dengan karakteristik jumlah anakan produktif dengan kisaran 15.8-25.9 anakan per lubang, umur panen kategori genjah, dan produktivitas $>5.4$ ton $\mathrm{ha}^{-1}$. Galur-galur tersebut yaitu MW3-12-1-3, MW3-36-1-1, MW3-58-2-3, MW3-821-1, MW6-60-1-1, YD1-48-1-2, YD1-51-2-1, YD1-51-2-2, YD1-61-1-1, YD1-71-1-1, YD5-10-1-2, YD5-37-1-1, YD537-1-2, dan YD6-1-1-1. Hasil tersebut menggambarkan bahwa galur-galur yang diperoleh memiliki sifat agronomi yang baik dan memiliki produktivitas tinggi sehingga dapat dilanjutkan pada uji multilokasi untuk mengetahui sifat stabilitas produktivitas. 
Tabel 3. Rata-rata keragaan karakter komponen hasil genotipe padi hitam dan nilai indeks terboboti

\begin{tabular}{|c|c|c|c|c|c|c|c|}
\hline Genotipe & $\begin{array}{c}\text { Jumlah } \\
\text { gabah isi per } \\
\text { malai }\end{array}$ & $\begin{array}{c}\text { Jumlah } \\
\text { gabah hampa } \\
\text { per malai }\end{array}$ & $\begin{array}{c}\text { Jumlah } \\
\text { gabah total } \\
\text { per malai }\end{array}$ & $\begin{array}{l}\text { Persentase } \\
\text { gabah isi per } \\
\text { malai }(\%)\end{array}$ & $\begin{array}{c}\text { Bobot } 1,000 \\
\text { butir gabah } \\
\text { bernas }(\mathrm{g})\end{array}$ & $\begin{array}{l}\text { Produktivitas } \\
\quad\left(\text { ton } \mathrm{ha}^{-1}\right)\end{array}$ & $\begin{array}{c}\text { Nilai indeks } \\
\text { terboboti }\end{array}$ \\
\hline MW3-12-1-3 & 88.6 & 36.9 & 125.5 & 70.0 & 28.6 & 5.8 & -2.99 \\
\hline MW3-12-1-4 & 87.7 & 29.2 & 116.8 & 72.6 & 28.7 & 5.6 & -3.69 \\
\hline MW3-24-2-1 & 71.8 & 24.2 & 95.9 & 72.5 & 27.5 & 5.3 & -7.65 \\
\hline MW3-36-1-1 & 82.6 & 15.3 & 97.8 & 84.1 & 26.8 & 6.0 & 2.39 \\
\hline MW3-36-1-2 & 81.9 & 10.6 & 92.5 & 88.3 & 25.9 & 5.7 & -0.07 \\
\hline MW3-58-2-3 & 95.7 & 21.1 & 116.8 & 81.5 & 28.3 & 5.9 & -0.18 \\
\hline MW3-58-2-4 & 78.3 & 23.8 & 102.1 & 76.6 & 29.4 & 4.9 & -10.39 \\
\hline MW3-82-1-1 & 85.6 & 30.9 & 116.4 & 72.8 & 28.4 & 5.9 & -1.06 \\
\hline MW4-40-1-2 & 76.4 & 32.4 & 108.8 & 70.4 & 28.2 & 5.6 & -2.19 \\
\hline MW5-19-1-1 & 108.4 & 16.5 & 124.9 & 86.4 & 23.6 & 5.1 & -5.40 \\
\hline MW6-60-1-1 & 146.9 & 19.9 & 166.8 & 86.6 & 21.0 & 5.5 & -0.88 \\
\hline YD1-61-1-1 & 114.3 & 49.0 & 163.3 & 72.1 & 25.9 & 6.2 & 1.81 \\
\hline YD1-71-1-1 & 121.6 & 48.5 & 170.0 & 73.3 & 25.1 & 6.6 & 4.44 \\
\hline YD1-51-2-1 & 138.1 & 33.1 & 171.2 & 80.5 & 24.3 & 6.2 & 4.41 \\
\hline YD1-51-2-2 & 142.2 & 34.3 & 176.5 & 80.7 & 24.6 & 6.1 & 4.15 \\
\hline YD1-51-2-3 & 140.4 & 39.6 & 180.0 & 78.3 & 23.8 & 5.2 & -3.88 \\
\hline YD1-48-1-2 & 133.5 & 49.0 & 182.4 & 70.8 & 24.5 & 5.8 & -0.57 \\
\hline YD5-10-1-2 & 148.5 & 42.3 & 190.8 & 76.6 & 22.5 & 6.3 & 4.98 \\
\hline YD5-37-1-1 & 176.0 & 89.1 & 265.0 & 67.1 & 25.7 & 6.0 & 4.50 \\
\hline YD5-37-1-2 & 175.4 & 104.2 & 279.6 & 61.9 & 23.4 & 5.6 & -0.67 \\
\hline YD5-37-1-3 & 140.1 & 53.7 & 193.8 & 71.4 & 26.3 & 5.1 & -6.15 \\
\hline YD6-1-1-1 & 151.0 & 39.6 & 190.6 & 78.6 & 25.2 & 5.8 & -0.21 \\
\hline YD6-1-1-2 & 167.8 & 61.9 & 229.8 & 71.2 & 25.0 & 4.9 & -6.71 \\
\hline Aek Sibundong & 96.6 & 31.8 & 128.4 & 75.7 & 30.6 & 6.9 & 10.34 \\
\hline Jeliteng & 158.2 & 38.0 & 196.1 & 78.5 & 22.2 & 5.8 & 0.32 \\
\hline Inpari 24 & 141.7 & 22.4 & 164.1 & 86.2 & 28.9 & 7.3 & 15.35 \\
\hline Rata-rata & 121.1 & 38.3 & 159.5 & 76.3 & 25.9 & 5.8 & \\
\hline BNT (0.05) & 16.0 & 15.8 & 22.2 & 8.3 & 1.5 & 1.3 & \\
\hline
\end{tabular}

\section{KESIMPULAN}

Interaksi $\mathrm{G}$ x E berpengaruh nyata pada semua karakter yang diamati kecuali pada karakter lama pengisian gabah. Seleksi dengan menggunakan indeks seleksi terboboti menghasilkan 14 galur yang memiliki sifat agronomi baik dan berdaya hasil tinggi yang dapat dilanjutkan untuk pengujian multilokasi. Galur-galur tersebut memiliki karakteristik jumlah anakan produktif dari 15.8 hingga 25.9, umur panen dengan kategori genjah, dan produktivitas $>5.4$ ton $\mathrm{ha}^{-1}$.

\section{UCAPAN TERIMAKASIH}

Ucapan terimakasih disampaikan kepada Departemen Agronomi dan Hortikultura, Fakultas Pertanian, IPB yang telah memberikan fasilitas dalam pelaksanaan kegiatan penelitian.

\section{DAFTAR PUSTAKA}

Alsabah, R., B.S. Purwoko, I.S. Dewi, Y. Wahyu. 2019. Selection index for selecting promising doubled haploid lines of black rice. SABRAO J. Breed. Genet. 51:430-441. 
Akbar, M.R., B.S. Purwoko, I.S. Dewi, W.B. Suwarno, Sugiyanta. 2019a. Penentuan indeks seleksi untuk galur dihaploid padi sawah tadah hujan berdaya hasil tinggi. J. Agron. Indonesia 47:111-118.

Akbar, M.R., B.S. Purwoko, I.S. Dewi, W.B. Suwarno, Sugiyanta. 2019b. Selection of doubled haploid lines of rainfed lowland rice in preliminary yield trial. Biodiversitas 20:2796-2801.

Akbar, M.R., B.S. Purwoko, I.S. Dewi, W.B. Suwarno, Sugiyanta, M.F. Anshori. 2021. Agronomic and yield selection of doubled haploid lines of rainfed lowland rice in advanced yield trials. Biodiversitas 22: 30063012 .

Anshori, M.F., B.S. Purwoko, I.S. Dewi, S.W. Ardie, W.B. Suwarno. 2019. Selection index based on multivariate analysis for selecting doubled-haploid rice lines in lowland saline prone area. SABRAO J. Breed. Genet. 51:161-174.

Anshori, M.F., B.S. Purwoko, I.S. Dewi, S.W. Ardie, W.B. Suwarno. 2021. A new approach to select doubled haploid rice lines under salinity stress using indirect selection index. Rice Sci. 28:368-378.

Cui, Y., R. Li, G. Li, F. Zhang, T. Zhu, Q. Zhang, J. Ali, Z. Li, S. Xu. 2020. Hybrid breeding of rice via genomic selection. Plant Biotech. J. 18:57-67.

Dewi, I.S., B.S. Purwoko. 2012. Kultur antera untuk percepatan perakitan varietas padi di Indonesia. J. AgroBiogen 8:78-88.

Gazal, A., F.A. Nehvi, A.A. Lone, Z.A. Dar, M.A. Wani. 2017. Smith hazel selection index for the improvement of maize inbred lines under water stress conditions. Int. J. Pure App. Biosci. 5:72-81.

Hidayatullah, A., B.S. Purwoko, I.S. Dewi, W.B. Suwarno. 2018. Agronomic performance and yield of doubled haploid rice lines in advanced yield trial. SABRAO J. Breed. Genet. 50:242-53.

[IRRI] International Rice Research Institute. 2013. Standard Evaluation System for Rice. INGER-IRRI, Manila, $\mathrm{PH}$.

Islam, M.R., M.O. Kayess, M. Hasanuzzaman, M.W. Rahman, M.J. Uddin, M.R. Zaman. 2017. Selection index for genetic improvement of wheat (Triticum aestivum L.). JCBPS. 7:1-8.

Mawaddah, B.S. Purwoko, I.S. Dewi, D. Wirnas. 2018. Karakterisasi sifat agronomi tanaman padi beras merah dihaploid berpotensi hasil tinggi diperoleh melalui kultur antera. J. Agron. Indonesia 46:126132.
Muthayya, S., J.D. Sugimoto, S. Montgomery, G.F. Maberly. 2014. An overview of global rice production, supply, trade, and consumption. Ann. N.Y. Acad. Sci.13:74.

Pratiwi, R., YA. Purwestri. 2017. Black rice as a functional food in Indonesia. Funct. Foods in Health Dis. 7:182194.

Raghuvanshi, R.S., A. Dutta, G. Tewari, S. Suri. 2017. Qualitative characteristics of red rice and white rice procured from local market of Uttarakhand: a comparative study. J. Rice Res. 10:49-53.

Ramos, H.C.C., M.G. Pereira, A.P. Viana, L.N. da Luz, D.L. Cardoso, G.A. Ferreguetti. 2014. Combined selection in backcross population of papaya (Carica papaya L.) by the mixed model methodology. Amer. J. Plant Sci. 5:2973-2983.

Sabri, R.S., M.Y. Rafii, M.R. Ismail, O. Yusuff, S.C. Chukwu, N.A. Hasan. 2020. Assessment of agromorphologic performance, genetic parameters and clustering pattern of newly developed blast resistant rice lines tested in four environments. Agronomy. 10:1098-1115.

Sandhu, S.K., M.S. Kang, M.W. Akash, P. Singh. 2019. Selection indices for improving selection efficiency in Indian mustard. J. Crop Improv. 33:25-41.

Seyoum, M, S. Alamerew, K. Bantte. 2012. Genetic variability, heritability, coefficient and path analysis for yield and yield related traits in upland rice (Oryza sativa L.). J Plant Sci. 7:13-22.

Shao, Y., Z. Hu, Y. Yu, R. Mou, Z. Zhu, T. Beta. 2018. Phenolic acids, anthocyanins, proanthocyanidins, antioxidant activity, minerals and their correlations in non-pigmented, red, and black rice. Food Chem. 239:733-741.

Silva, L.A., R.T. Resende, R.A.D.C. Ferreira, G.N. Silva, V. Kist, M.H.P Barbosa, M. Nascimento, L.L. Bhering. 2016. Selection index using the graphical area applied to sugarcane breeding. Genet. Mol. Res.15:1-13. Doi: 10.4238/gmr.15038711.

Singh, R.K., B.D. Chaudhary. 1979. Biometrical Methods in Quantitative Genetic Analysis. Kalyani Publisher. New Delhi, IND.

Sivakumar, V., K. Uma-Jyothi, C. Venkataramana, R. Rajyalakshmi. 2017. Stability analysis of Brinjal (Solanum melongena) hybrids and their parents for yield and yield components. SABRAO J. Breed. Genet. 49:9-15. 